\title{
Sugar Daddy: Gilberto Freyre y el amor entre blancos y negros
}

Sugar Daddy: Gilberto Freyre and love between whites and blacks

Sugar Daddy: Gilberto Freyre e o amor entre brancos e negros

\section{César Braga-Pinto}

NORTHWESTERN UNIVERSITY, ESTADOS UNIDOS

Profesor asociado en el Departamento de Español y Portugués de la

Universidad de Northwestern. PhD por la Universidad de California

en Berkeley. Actualmente, investiga sobre amistad masculina y

sociabilidad interracial en el Brasil de fines del siglo XIX. Es autor

de As Promessas da História: Discursos Proféticos e Assimilação

no Brasil Colonial (EdUSP, 2003) y editor de Ligeiros Traços:

escritos de juventude de fosé Lins do Rego (Jose Olympo, 2007).

Asimismo, es coeditor - junto con Fátima Mendonça- de foõo

Albasini e as luzes de Nwandzenguele: literatura e política em

Moçambique 1908-1922 (Alcance, 2014) y de À Procura de Saúde:

crônicas de um doente / In Search of Health: chronicles of a sick

man (Alcance, 2015). Su próximo libro se titulará A Violência das

Letras: Amizade e inimizade na literatura brasileira (1888-1940)

(EdUERJ). Correo electrónico: c-braga-pinto@northwestern.edu

\section{Artículo de reflexión}

Artículo publicado, originalmente, como "Sugar Daddy: Gilberto Freyre and the white man's love for blacks", en el volumen The Masters and the Slaves: Plantation Relations and Mestizaje in American Imaginaries, editado por Alexandra Isfahani-Hammond (New York: Palgrave, 2005), 19-33. Esta traducción al español fue realizada por José Delpino Vivas y revisada por Cristián Opazo. Se mantendrá el anglicismo Sugar Daddy con el fin de dar más contundencia a la expresión slang y dejar la marca. La expresión en español se refiere a un hombre viejo y adinerado que obsequia con regalos costosos a mujeres jóvenes a cambio de favores sexuales (N. del T.).

Documento accesible en línea desde la siguiente dirección: http://revistas.javeriana.edu.co 


\section{Resumen}

Este ensayo se enfoca en las representaciones de la homosexualidad en el trabajo de Gilberto Freyre (1900-1987), particularmente, en la manera en que tales figuraciones alteran las nociones de contacto racial y mestizaje. Al echar una mirada a la configuración de los "deseos homosociales" en algunos de los textos de Freyre, se puede entender el rol que las narrativas de relaciones interraciales y homosexuales desempeñan en la estructuración de lo que él llama "la familia patriarcal brasilera" y, de este modo, en la representación canónica de Brasil como nación mestiza.

Palabras clave: Gilberto Freyre; deseo; homosociabilidad; mestizaje; nación

\section{Abstract}

This essay focuses on the representations of homosexuality in the works of Gilberto Freyre (1900-1987), particularly in the way in which such figurations change the notions of racial contact and miscegenation. By looking at the configuration of the "homosocial desires" in some of Freyre's texts, we can understand the role that the narratives of interracial and homosexual relations play in structuring what he calls "the Brazilian patriarchal family" and, thus, the canonical representation of Brazil as a mestizo nation.

Keywords: Gilberto Freyre; desire; homosociability; miscegenation; nation

\section{Resumo}

Este ensaio foca nas

representações da

homossexualidade no trabalho de Gilberto Freyre (1900-1987), particularmente na forma em que tais figurações alteram as noções de contato racial e miscigenação. Ao estudar a configuração dos "desejos homossociais" em alguns dos textos de Freyre, pode-se entender o papel que as narrativas de relações interraciais e homossexuais desempenham na estruturação do que ele chama de "a família patriarcal brasileira" e, desta forma, na representação canônica do Brasil como nação mestiça.

Palavras-chave: Gilberto Freyre; desejo; homossociabilidade; miscigenação; nação

RECIBIDO: 15 DE JULIO DE 2016. ACEPTADO: 19 DE DICIEMBRE DE 2016. DISPONIBLE EN LÍNEA: 29 DE DICIEMBRE DE 2017

\section{Cómo citar este artículo:}

Braga-Pinto, César. "Sugar Daddy: Gilberto Freyre y el amor entre blancos y negros". Cuadernos de Literatura 21.42 (2017): 79-95. https://doi.org/10.11144/Javeriana.cl21-42.sdgf 


\section{Ambivalencias coloniales}

El trabajo sociológico híbrido de Freyre, Casa Grande e Senzala - escrito en 1933- fue uno de los primeros esfuerzos para pensar Brasil como una sociedad multirracial y multicultural, y para concebir el mestizaje en términos positivos. Freyre pasó la mayor parte de su vida interpretando las relaciones entre los portugueses y otros pueblos, y creó una narrativa en la que el colonizador surge como un sujeto tolerante, flexible o, como escribe con frecuencia, plástico. Para Freyre, los portugueses se caracterizan por su miscibilidad, o su capacidad para adaptarse a otras regiones, climas y culturas. En los cincuenta, tales ideas se cristalizaron en una noción llamada lusotropicalismo, neologismo que señala la cualidad singular de los portugueses para aclimatarse a los trópicos. Estas ideas fueron apropiadas subsecuentemente por el dictador portugués Salazar - de quien Freyre fue un gran admiradorpara justificar el colonialismo portugués en África.

Casa Grande e Senzala - versión aquí comentada - examina la herencia brasileña hasta el encuentro entre los pueblos portugueses, africanos e indígenas en la sociedad de la plantación de caña de azúcar de los primeros siglos de la colonización en Brasil. A pesar de su esfuerzo por celebrar el mestizaje, Freyre ve las relaciones interraciales como la causa de ciertas aberraciones históricas y, en numerosas instancias, asocia el contacto racial con la enfermedad y la degeneración social. Tal es el caso en un pasaje del primer capítulo de Casa Grande e Senzala, en el cual Freyre pugna por disociar el mestizaje del contagio por medio de una discusión en extremo enrevesada:

[...] La ventaja del mestizaje en Brasil va de la mano de las tremendas desventajas de la sífilis. Estos dos factores empezaron a operar al mismo tiempo: uno en la formación del brasilero, el tipo ideal de hombre moderno de los trópicos, un europeo con sangre negra o indígena que aviva su energía; el otro que lo deforma. A partir de lo anterior surge cierta confusión de pensamiento con respecto a las responsabilidades, muchos atribuyen al mestizaje efectos que provienen principalmente de la sífilis, así, la raza negra o la amerindia, incluso la portuguesa han sido juzgadas responsables de la "fealdad" y la "ignorancia" de aquellos de nuestras poblaciones periféricas que se han visto más afectados por la sífilis o comidos por los gusanos, mientras que la verdad es que cada una de estas razas, en estado de pureza y sin entrecruzamientos, se ha agotado de producir ejemplos admirables de belleza y vigor físico. (70-71; énfasis del autor) 
De acuerdo con Freyre, la colonización tiene ventajas y desventajas, pero el mestizaje debe entenderse desde su valor positivo como una dimensión de la "civilización". Esto significa que el hombre ideal para el trópico es un europeo cuya energía ha sido reactivada por el contacto con pueblos africanos e indígenas. El "buen" mestizaje es la infusión nutritiva de la civilización europea con sangre indígena y africana, un término ambiguo que mezcla los significados de genética y herencia cultural contenidos en el mestizaje con una historia de violencia y muerte sacrificial.

En contraste con este "buen" mestizaje que es sinónimo de civilización, Freyre reintroduce la amenaza de la degradación física a través del mestizaje y atribuye esto a los efectos de la sífilis o, en su lenguaje lúdico, a la sifilización. Aunque Freyre sugiere, en contravía de la opinión general, que los europeos fueron quienes introdujeron la sífilis en el Nuevo Mundo, con frecuencia enfatiza que los portugueses contraían la sífilis a través del intercambio sexual con brasileños de raza negra o indígenas. Aunque la mezcla racial puede no ser la causa de la sífilis, el contacto sexual interracial permanece como contexto para explicar la manera en que la sociedad brasileña se formó y de-formó. De este modo, la sifilización, que ante todo caracteriza al mestizo del interior, se corresponde con el espectro negativo de la civilización, es decir, del verdadero mestizaje - que, de nuevo, tiene que ver con una cultura europea "energizada" o imbuida por "sangre" africana o indígena-. En otras palabras, incluso si Freyre pretende celebrar la herencia africana e indígena de Brasil, esta herencia será siempre ambivalente, y el panorama que resulta de esto oscila entre lo simbólico y lo genético. A la vez que Freyre sugiere que el hombre mestizo puede haberse degenerado como resultado de una historia de contacto racial (representado por la sifilización), sugiere, también, que la herencia genética y cultural resultante de la economía de la plantación de la caña de azúcar ha reactivado la energía y ha incrementado la potencia del hombre blanco.

En otro pasaje sugestivo y ambivalente, Freyre discute las consecuencias de la división de labores en la sociedad de la plantación, y concluye que el resultado es el siguiente:

Cada señor blanco de la mansión fue abandonado con dos manos izquierdas, y todo hombre negro con dos manos derechas [.. . el el cuerpo del hombre blanco se convirtió exclusivamente en un miembro viril. Ahora tiene las manos de una mujer, los pies de un niño y solo su sexo se tornó arrogante y viril. En contraste con los negros - la mayoría eran gigantes enormes, pero sus penes son como los de niños. (429) 
Con seguridad, la explicación metafórica de Freyre sugiere que la sociedad de la plantación explotó la labor física del hombre negro, haciendo del hombre blanco un inepto para el trabajo. A lo largo y ancho de su obra, Freyre procura demostrar los resultados positivos y negativos de una colonización que se basó en el trabajo esclavo y la economía de la plantación. Quiere contravenir las teorías evolucionistas y eugenésicas en boga, las cuales declaraban que el contacto racial y el mestizaje suponían una fuente de degeneración. De este modo, él justifica cualquier resultado negativo de la mezcla racial en términos históricos más que en términos genéticos. De una parte, Freyre enfatiza en un parentesco original o una simbiosis entre blancos y negros; de otra, como se puede deducir de las figuras andróginas y monstruosas que imagina como legado de la economía de la plantación, el autor de nuevo despliega una retórica que asocia el contacto racial con la amenaza de la degeneración física - a pesar de que se podría argumentar que el cuerpo se presenta como metáfora de la sociedad como un todo-. Más aún, la insistencia de Freyre sobre el contraste entre los tamaños de los genitales de negros y blancos sugiere no solo un contacto que es esencialmente sexual sino, más importante todavía, una relación que es fundamentalmente asimétrica. Si, como Freyre sugerirá posteriormente, el mestizaje es una manera de interpenetración entre blancos y negros, resulta innecesario hacer hincapié en la manera en la cual algunos se encuentran más penetrados que otros.

Al principio de Casa Grande e Senzala, de algún modo, Freyre asocia la historia precolonial de Portugal y la supuesta inclinación de los portugueses hacia el mestizaje con, si no la homosexualidad, sí, por lo menos, la bisexualidad. Freyre insiste en la noción de la "flexibilidad desinhibida" de los portugueses así como en su tendencia hacia un "equilibrio de antagonismos". Le atribuye estas características a su situación geográfica e historia única de "bi-continentalismo", la cual compara con la "bisexualidad":

En su indeterminación étnica y cultural entre Europa y África, Portugal parece haber sido igual a otras porciones de la península. Una especie de bi-continentalismo que, en una población tan vaga y mal definida, se corresponde con una bisexualidad en el individuo. Sería difícil imaginar un pueblo más fluctuante que el portugués; el débil equilibrio de antagonismos que se percibe en todo aquello que le atañe, lo cual le confiere una flexibilidad que en ocasiones se encuentra perturbada por su lamentable vacilación, a la par de una riqueza especial en aptitudes que con frecuencia discrepan y son difíciles de reconciliar para fines comunicativos eficaces o iniciativas prácticas. (7) 
Así pues, Freyre postula que, por razones históricas, los portugueses carecían de una consciencia de raza y, por tanto, no podían haber sido racistas del mismo modo en que los anglosajones lo fueron en Norteamérica. Intriga que Freyre asocie abiertamente la ambivalencia étnica de los portugueses con la flexibilidad ambivalente de su sexualidad. Si se hace una lectura cuidadosa, parece que Freyre sugiere que la bisexualidad - no la androginia, como cabría esperarse - del mismo modo que el "indeterminismo" racial, es una inclinación específicamente portuguesa —¡muy positiva, por demás!- ¿ ¿Se puede concluir que, para Freyre, los portugueses carecen de conciencia de género y, por esta razón, no tienen ninguna inclinación a la homofobia?

El hecho es que cuando Freyre discute la historia temprana de la herencia africana en Brasil, con frecuencia describe la relación entre el amo blanco y el esclavo negro en términos sexuales. El hombre negro es con frecuencia el objeto y el compañero central en la iniciación sexual del joven adolescente blanco - lo cual para Freyre confirma la virilidad portuguesa y su disposición hacia el sexo, dado que el hombre negro es con frecuencia representado en un rol femenino-. Ya en 1928, en su Manifesto regionalista, Freyre celebraba las "contribuciones" de África a la cultura de los descendientes portugueses, al feminizar la imagen del hombre negro. Desde esta perspectiva, el hombre negro no es antagonista del hombre blanco, al contrario, voluntariamente coopera e incluso le sirve en todo sentido, tanto en la mesa como en los arbustos. Freyre define a los portugueses como jóvenes y hombres glotones, que "siempre están listos, en una manera franciscana, a fraternizar ["confraternizar"] con sus hermanos negros y pardos" (Manifesto 69). Para Freyre, esto explicaría la creciente influencia amerindia y africana sobre la mesa y los dulces ("mesa e sobremesa") de los colonizadores, debido a la mediación no solo de jóvenes mujeres ("cunhas") y "negras minas", sino también de cocineros o "mestre-cucas": generalmente hombres negros grandes y afeminados ("pretalhões amaricados") (68).

De esta manera, incluso si Freyre escribe en términos de "relaciones fraternales" entre negros y blancos, la penetración colonial interracial que él imagina puede difícilmente entenderse como una forma de amor fraterno. De hecho, Freyre discute explícitamente los intercambios sociales y sexuales entre negros y blancos en términos de un sadomasoquismo inherente a la historia del encuentro colonial - aquello a lo que Freyre llama "sadismo del amo" y el correspondiente "masoquismo esclavo" (CGS 51$)$ - . Sin embargo, pese a esta aparente violencia, el encuentro interracial acaba por ser complementario más que antagónico. Ultimadamente, el "equilibrio de antagonismos", que Freyre 
define con insistencia como la esencia de la formacao brasileira, consiste en un equilibrio armónico entre el sadismo de las élites y el masoquismo de las masas, de las cuales, las últimas en raras ocasiones se sublevaron y cuando lo hicieron fue en movimientos rituales o mesiánicos (51).

De manera que para entender la democracia racial y el lusotropicalismo se debe tener en perspectiva no solo el modo en que se da el mestizaje de las relaciones entre hombres portugueses y mujeres africanas e indígenas, sino, también, de acuerdo con Freyre, esa forma particular de homosociabilidad que se articula en los trópicos, es decir, en el escenario colonial. En la siguiente sección, se discutirán la conceptualización de las relaciones homosociales de Freyre (es decir, dentro del mismo grupo étnico) y la manera en que la inclusión de las negritudes perturba la imagen de una sociedad constituida por lazos de amistad y fraternidad. En su esfuerzo por representar una sociedad multirracial y fraternal, Freyre combina un número de ansiedades y tabúes, en particular aquellos concernientes al contacto racial, la homosexualidad y el incesto.

\section{El hombre blanco y sus hermanos negros}

No solo en las novelas americanas el significado más noble del término amistad se ha querido entender tradicionalmente como relación espiritual entre hombres. En su conocido ensayo, "De la amistad", Michel de Montaigne (1533-1592) postula que las mujeres "en ningún caso han logrado alcanzarla, y por el común acuerdo de la antigua usanza se encuentran excluidas de ella" (138). Para Montaigne, la amistad verdadera debería ser una "alianza entre hermanos" que "se alimente de la comunicación" (136). El ensayista francés la entiende como una "armonía de voluntades" (137) o como una "fusión de voluntades" (141). A diferencia de la relación entre padre e hijo, o de aquella "otra, el amor licencioso griego, el cual es justamente aborrecido por nuestra moralidad" (138), Montaigne define la verdadera amistad como perteneciente a una "clase más equitativa y ecuánime" (139). El amor (homosexual) de los griegos, argumenta, no puede ser definido como amistad porque, por otro lado, involucró "una disparidad necesaria en edad y (así mismo) una diferencia en las funciones de los amantes"; más aún, se "basó simplemente en la belleza externa, la imagen falsa de la generación corporal" (138). Para Montaigne, la amistad debe estar fundamentada en algo más que la apariencia física, mientras, a la vez, debía involucrar una cierta igualdad de estatus o equilibrio de fuerzas entre las dos partes. 
En Politiques de l'amitié, el filósofo francés Jacques Derrida argumenta que no solo la noción occidental de amistad se ha fundamentado tradicionalmente en el concepto de fraternidad sino que, también, nuestras nociones de democracia e, incluso, de humanidad se encuentran concebidas en tales términos. En tanto Derrida traza la canonización del concepto occidental de amistad como la representación de amor fraterno, formula la siguiente pregunta: " ¿Cómo puede aquello excluir lo femenino o la heterosexualidad, la amistad entre mujeres o la amistad entre un hombre y una mujer? ${ }_{\mathrm{i}}$ Por qué no se puede hallar ningún registro esencial de experiencias de amistad femeninas o heterosexuales? ¿iPor qué semejante heterogeneidad entre el eros y el philia?" (308).

Ni Montaigne ni Derrida discuten el sitio de la raza o la etnicidad en la definición o canonización de la amistad, pero se podrían incluir las siguientes preguntas: ¿cómo es que la amistad, entendida como amor fraterno, ha excluido esa otra heterogeneidad fundamental histórica, concretamente, la diferencia racial (y tal vez también étnica)? ¿Acaso la construcción de relaciones entre negros y blancos no se ha concebido (en la tradición occidental) como un paralelo frente a las relaciones heterosexuales y, por tanto, como simétricas e incapaces de constituir una "amistad verdadera", por lo menos en sociedades en las que la historia se ve caracterizada por el colonialismo y la esclavitud? Si las representaciones occidentales de las relaciones entre negros y blancos han sido con frecuencia sexualizadas (como si esas relaciones que no pueden constituir una forma de philía, entraran necesariamente en el ámbito del éros), ¿cómo se pueden definir, al interior de las sociedades multirraciales modernas, las fronteras entre el racismo y la homofobia? Si la democracia se entiende en términos de amistad y amor fraterno, ¿cómo se puede interpretar la famosa expresión "democracia racial", que ha sido asociada con las ideas de Freyre? ${ }^{1}{ }_{\mathrm{C}}$ Es posible imaginar un modelo no

1 Hermano Vianna, en uno de sus usuales gestos críticos "para salvar a Freyre de Freyre", señala que en ninguna parte de Casa-Grande e Senzala él emplea la expresión "democracia racial" (2000). Esto es cierto, tal vez Freyre nunca la empleó en ninguno de sus escritos, pero no es gratuito o producto de pobres lecturas que "la democracia racial" se haya asociado con su trabajo. En El nuevo mundo en los trópicos, por ejemplo, Freyre escribe acerca de "La amalgamación de razas y la democracia étnica y social en Brasil" (71); también escribe que "probablemente en ninguna otra comunidad moderna los problemas de raza son relaciones que se solucionan en una forma más democrática o cristiana que en la América portuguesa" (121); y que "Brasil se ha convertido en una comunidad conocida por su inclinación hacia la democracia étnica" (167). Resulta también muy interesante 
consanguíneo de amistad/hermandad? ¿Es la noción de un Brasil como "democracia social" verdaderamente multirracial y multicultural?

Leslie Fiedler fue probablemente el primer crítico literario en discutir las interacciones entre homosexualidad y raza en la novela norteamericana. En un artículo seminal que, sin embargo, es poco conocido fuera del campo de los estudios americanos, Fiedler sugiere que la construcción de "un mito nacional de amor masculino" en los Estados Unidos se encuentra contrariada por la existencia del amor homosexual y por la relación inestable entre negros y blancos en la sociedad americana. La castidad e inocencia de este amor imaginado, que siempre es superior a la representación vulgar del amor heterosexual es, de acuerdo con Fiedler, uno de los mitos fundacionales americanos. El autor arguye que, desde el Huckleburry Finn de Mark Twain hasta Moby Dick de Herman Melville, y más allá, la representación del amor entre hombres se encuentra en el centro de la novela americana.

Esta es una forma de amor que es ciertamente físico, pero que no puede llamarse sexual solo porque está protegido por cierta "ignorancia infantil" (Fiedler 7). Más aún, en obvia contradicción con la realidad de la sociedad norteamericana, en la ficción clásica americana, el amor masculino tiene lugar entre un blanco y un moreno o negro. Este amor ficcional, al que Fiedler llama "el sueño profundo de amor en nuestras relaciones con el Negro" (8), es muy superior al amor heterosexual hacia la mujer negra puesto que, aunque interracial, en el primer caso nunca llevará al mestizaje: "En tanto no haya mezcla de sangres, el alma puede copular con el alma en el bosque inmaculado de Dios" (9). De acuerdo con el crítico americano, esto supone más que un sueño de reconciliación; es el deseo de la aceptación total, más allá de la culpa o de la necesidad de perdón: el hombre negro o moreno "nos consolará, como si nuestra ofensa contra él hubiese sido hace mucho tiempo aplacada, como si jamás hubiese sido real" (11). Fiedler concluye que más allá de la pesadilla del americano blanco que un día ya no será más un turista, un heredero o un liberador al que se le niega, al que se rechaza, está el sueño de su aceptación en el seno al que ha ofendido de manera tan

darle una mirada a la traducción inglesa del texto Sobrados e Mocambos (Las mansiones y la chabolas) que hiciera Harriet de Onís. El texto inglés fue editado y modificado, con el permiso de Freyre, y concluye con la siguiente oración, la cual no se encuentra en la versión portuguesa: "Dado que Brasil se ha vuelto cada día más una democracia racial, caracterizada por una combinación casi única de diversidad y unidad" (431). 
deliberada. Es un sueño tan sentimental, tan extravagante, tan desesperado, que redime nuestro concepto de juventud de la nostalgia a la tragedia. (11)

Aquí no se busca - y no está en las capacidades de este ensayo - discutir los límites de la interpretación que Fiedler hace de la imaginación literaria americana, aunque los términos de su discusión, se puede afirmar, parecen bastante iluminadores. Solo recientemente estos términos se han convertido en interés central de los estudios literarios y queer. En particular, Fiedler anticipa la aparición de nociones como continuum homosocial y pánico homosexual, ambos acuñados por Eve Sedgwick en Between Men: English Literature and Male Homosocial Desire, en el que propone que "para trazar lo homosocial hasta la órbita del deseo, de lo potencialmente erótico, entonces, hay que hipotetizar la ininterrupción potencial de un continuum entre lo homosocial y lo homosexual - un continuum cuya visibilidad, para los hombres, en nuestra sociedad, está radicalmente perturbada" (1-2). A lo largo de las mismas líneas, Fiedler sugiere que llamar amor a la sexualidad entre hombres sería como "la profanación de un sueño" (9). Las perspectivas de Fiedler, como la articulación teórica de los deseos homosociales de Sedgwick, pueden arrojar nueva luz sobre la representación de la amistad interracial y el amor homosexual en la literatura brasileña. Más aún, aquí se piensa que, al mirar detenidamente las fracturas leves en "el continuum homosocial", se puede entender mejor el proceso de las categorías de redefinición y renegociación de raza y clase que se establecieron en Brasil durante la década de 1930.

En contraste con la interpretación que Fiedler hace de la literatura americana, aquello que llama la atención de la ficción brasileña es que las relaciones entre hombres blancos y negros no se conciben como algo inocente. O Bom Crioulo, texto escrito en 1895 por Adolfo Caminha (1867-1897), es considerada la primera novela que tomó el amor homosexual - una relación homosexual entre un hombre negro y uno blanco - como tema central. Mientras que la pareja interracial masculina en la ficción de Estados Unidos oculta un miedo familiar de mestizaje, en el Brasil posterior a Freyre tal ansiedad no existe; por el contrario, la mezcla racial se celebra, con frecuencia como una panacea para las tensiones y contradicciones heredadas de una historia de colonialismo y esclavitud. Para entender mejor el rol de la pareja masculina interracial en el trabajo de Freyre, se debe primero observar la manera en que las relaciones homosociales han sido representadas - en general, así como en 
Freyre- en el contexto de comunidades que de alguna manera son homogéneas, es decir, dentro de grupos étnicos o raciales.

En Casa Grande e Senzala, Freyre discute el rol de los lazos fraternos en la constitución de comunidades. En una sección de su libro acerca de "la contribución" indígena a la sociedad brasileña, el autor describe ciertas formas primitivas de sociabilidad masculina - a las que llama homomixiaentre los Bororo. Esta forma de sociabilidad, escribe, se manifiesta al interior de sociedades masculinas secretas que los Bororo llamaban "baito". De acuerdo con Freyre, el propósito de estas sociedades, que surgieron de manera "natural, y sin la sensación del acto pecaminoso" (118), era el de "afirmar el prestigio del hombre sobre la mujer" (118). Aunque tales sociedades suponían un fortalecimiento de los vínculos fraternales, Freyre señala que estos vínculos siempre fueron potencialmente sexuales: "[l] as afinidades que se elogiaban eran siempre las fraternas, de hombre a hombre; es decir, de afección viril. El resultado fue un medio favorable para la homosexualidad" (136). "La homomixia", así, es un espacio homosocial en el cual los individuos, del mismo sexo y de diferentes grupos sociales o étnicos, en otras palabras, los "hermanos", fortalecen sus vínculos sociales al enfatizar sus privilegios sobre las mujeres y, tal vez, también, sobre otros hombres; es, por ende, una práctica que es siempre potencialmente (homo) sexual. Freyre parece articular una continuidad potencial y, con ella, conveniente de relaciones masculinas, aunque no desafía las interdicciones homofóbicas ni los tabúes que estructuran las sociedades patriarcales occidentales.

Las fronteras entre actos homosexuales y pactos homosociales son, de hecho, uno de los temas favoritos de Freyre. En sus diarios - que asegura haber escrito durante su adolescencia, habiendo empezado a los quince años - se refiere a la homosexualidad en varias ocasiones. En un fragmento de 1922, en Oxford (para entonces contaba con veintiún años), aparece el siguiente testimonio, algo ambivalente, acerca de un recuerdo de lo que es de hecho una "decepción" o un evento que jamás ocurrió: "[a]hora recuerdo que en mis días colegiales, nunca tuve una experiencia homosexual. Fui casi un ángel. Hubiera sido un ángel en mi totalidad de no ser por una solitaria y recíproca masturbación - que raramente practiqué" (Tempo 104). Posteriormente, Freyre sugiere que presenció (si acaso no experimentó) una conducta homosexual en sus viajes a Oxford y Berlín:

En Oxford, no es extraño ver bailar jóvenes hombres entre sí [...] se trata de bailes que en ocasiones terminan en besos y abrazos. La verdad, sin embargo, es que semejantes arrebatos no son tan frecuentes aquí como lo son en la 
Alemania de la postguerra. Allá, el mito de la "raza de los amos" se corresponde a un masoquismo sexual de parte de los jóvenes alemanes, los más señoriales de entre ellos parecen deleitarse en el dolor que les suelen causar hombres morenos y exóticos. En Oxford, lo que uno encuentra es, más bien, la inclinación a una amistad intensa entre hombres jóvenes, parecida a la que existió - supongo - entre los griegos platónicos. Eventualmente pueden contener algo homosexual, pero casi siempre - así me lo parece - terminan por ser solo una homosexualidad transitoria, sin la consumación que en Recife le dio fama al inteligentísimo y cultivado cónsul de S.M.B., Mr. D. (102-103)

Más que especular acerca de la orientación sexual de Freyre, lo que concierne a este texto es el contraste entre los actos sexuales de alemanes con hombres morenos y exóticos - los cuales reproducen las dinámicas de señor-esclavo a la vez que las invierten - y la sociabilidad masculina británica (o griega), que coincide con el amor fraterno de Montaigne, un amor que debería ser principalmente (pero no exclusivamente) espiritual. En otras palabras, así como en las sociedades homosociales Bororo, incluso si estas relaciones fraternas se tornan físicas, esto debería ser ocasional y de ningún modo devenir en hábito o definir una forma asimétrica en las relaciones señor-esclavo. Tales formas de "homosexualidad transitoria" son aceptables en tanto su propósito sea el de enseñar y reforzar los vínculos fraternos de hombres de un mismo historial étnico, racial o cultural, a la vez que se debe enfatizar en la exclusión de las mujeres del espacio social masculino. Los actos homosexuales de los alemanes se entienden como una forma de perversión no solo porque son asimétricos, sino, y esto es tal vez más importante, porque invierten las oposiciones superior/inferior, masculino/femenino y señor/esclavo - ultimadamente, porque definen no solo las prácticas, sino también las identidades-.

La distinción entre amistad (que puede incluir la homosexualidad transitoria) y la pederastia es el tema central de dos de las novelas de Freyre, Dona Sinhá e o Filho Padre (1964) y su secuela, O Outro Amor do Dr. Paulo (1977). Ambas novelas describen la relación entre un joven blanco, de andrógino nombre, José María, y su amigo mestizo, Paulo Tavares. Más que analizar estos trabajos, aquí se prefiere citar las aproximaciones propuestas por Jossianna Arroyo en su ensayo "Homoeróticos brasileros", en el cual la autora relaciona "la reconciliación cultural de opuestos en la cultura brasilera" con la noción de Freyre de "escritura bisexual" (61). De acuerdo con Arroyo, la "subjetividad cultural (de Freyre) se basa en una alianza homosocial que 
difumina las líneas raciales para construir una 'hermandad nacional" (62), la cual combina "una mirada privilegiada con un nuevo sentido de hermandad, una masculinidad sensible" (77). Arroyo señala que en Dona Sinhá e o Filho Padre, el narrador describe la relación entre los dos personajes masculinos como una "amistad peligrosa, que desde el principio tenía un toque de amor o un qué se yo sexual", mientras que en la secuela, O Outro Amor do Dr. Paulo, después de la muerte de su amigo, Paulo Tavares "passara a considerá-lo, sublimando um afeto ante outro, um irmao mais moco que nao tivera e sempre desejara ter. Passou a amá-lo idealmente". Arroyo concluye que "para Paulo Tavares, la escritura se transforma en la búsqueda de la otra parte de su subjetividad, convirtiéndose en la personificación de una "feminidad masculina", y que el ideal de "fantasía cultural" es un hombre femenino más que una mujer masculina" (73-74).

Como antes se sugirió, aquí esto se ve de manera ligeramente diferente. Lo que vale la pena enfatizar es que si las dos novelas de Freyre de algún modo intentan incluir o, mejor, absorber lo mestizo en lo homosocial, la amistad espiritual que debería caracterizar a la sociedad civil, el hombre negro permanece fuera de la sociedad civil y plantea una amenaza (homosexual) para la constitución de una subjetividad (multirracial y multicultural) brasileña. Esta ansiedad muestra cómo la representación de una sociedad democrática como forma de hermandad atravesó transformaciones específicas con una demanda creciente por la inclusión del hombre negro en la sociedad civil, transformaciones que implicaron un número de contradicciones que Freyre tuvo problemas para resolver. De este modo, en tanto el mestizo sobrevive al hombre negro y al blanco, en su persona y estatus retiene la memoria de la hermandad imaginada entre ambas razas. Pero la verdadera herencia racial - la dimensión genética de la hermandad- es finalmente suprimida en el nombre de una nación mestiza culturalmente conceptualizada. Al final, los vínculos sociales fraternos pueden lograr una forma de hermandad espiritual opuesta a una física o biológica; en otras palabras, ambas son des-racializadas y asexualizadas.

Es evidente que la "democracia racial" de Freyre no siempre incluye el deseo homosocial, también se encuentra sustentada por la hipervirilidad del hombre portugués - a quien describe como el donjuán por excelencia y por sus intercambios eróticos con mujeres negras-. Pero el rol sexual de las mujeres negras corrobora una de las situaciones que Sedgwick estudió, allí "la planificación de la ruta del deseo homosocial a través de la mujer es claramente forzosa" (Between 49). Los hombres blancos y las mujeres negras no constituyen una familia ni ningún tipo de vínculo social, por lo contrario, las mujeres participan 
en el constructo social solo en tanto median en el contacto entre hombres negros y blancos, en ocasiones como objetos sexuales, en otras como nodrizas ("mae preta" o "madres negras" son sinónimos de "nodriza" en el portugués brasileño). Más aún, como Vera Kutzinski lo sugiere en Sugar’s Secrets, en relación con el rol de las mulatas en la literatura cubana, el concepto de mestizaje "es un tropo de mezcla racial sin participación femenina" (172), que representa "el nacimiento de una nueva raza de hombres" (178). La disquisición que Kutzinski hace del poeta cubano Nicolás Guillén es también pertinente para acercarse a los trabajos preliminares de Freyre:

Una vez que se elimina la desordenada participación (sexual) femenina en los procesos históricos de mezcla racial por irrepresentable, el mestizaje se legitima como un proyecto exclusivamente masculino o como un logro en el que la violación interracial heterosexual puede refigurarse como una aceptación a lo largo de las líneas de color (y, en este caso, de clase) y, significativamente, a través del cuerpo femenino borrado por la violación. Las connotaciones homoeróticas de esta aceptación y la apropiación concomitante de la función reproductiva de la mujer en la forma de creatividad masculina no pueden pasarse por alto. $(168)$

Más allá del ausentamiento de lo femenino, Freyre difumina la participación del hombre negro en el mestizaje, puesto que lo define como femenino y sitúa al hombre blanco en una posición superior de poder que es, de algún modo, más natural. Como se demostró antes, aunque Freyre expone con frecuencia el contacto racial en términos de "interpenetración", los hombres negros y blancos se sitúan siempre en posiciones asimétricas, con un poder desigual para penetrar el uno en el otro (de acuerdo con su lenguaje, su contacto hace que el pene de uno de ellos se haga cada vez más grande, mientras que el del otro se hace cada vez más pequeño). De este modo, cuando Freyre asocia la indeterminación sexual de los portugueses con su ambigüedad racial, la bisexualidad resultante no representa una amenaza para su masculinidad, tampoco los hace menos europeos, menos blancos o, incluso, menos heterosexuales. Tan paradójico como parece, la naturaleza bisexual y birracial de la noción de mestizaje que tiene Freyre no perturba la hegemonía del hombre portugués blanco y heterosexual. Dado que los "flexibles" portugueses son esencialmente propensos a asimilar influencias externas, se vuelven cada vez más portugueses o, por lo menos, más luso-brasileños, en la medida en que incorporan la cultura africana; más aún, el adolescente blanco portugués se hace cada vez más hombre en la medida en que haga intercambios de favores con sus "hermanos negros". El modelo ho- 
mosexual (y el heterosexual también) de intercambio entre negros y blancos se asimila como una fase en el desarrollo del niño brasileño en la sociedad de la plantación, así como en la historia de la nación mestiza. En la misma medida en que los griegos asociaban la homosexualidad (temporal) con un propósito pedagógico, quizá Freyre también sugiere que los lazos entre hombres negros y blancos sirven a un propósito civilizador.

En conclusión, se podría afirmar lo siguiente: (1) Las relaciones homosexuales entre grupos étnicos son aceptables en la medida en que son temporales y sublimadas, en últimas, a una "fusión de voluntades" (Montaigne) o una "mezcla de almas" (Fiedler 2). Las relaciones interraciales homosociales se encuentran más marcadas por su sexualidad que aquellas que se dan dentro del mismo grupo étnico o racial; para convertirse en una amistad "verdadera", debe desracializarse puesto que - quizá del mismo modo Montaigne percibía a la mujer- Freyre considera a los negros incapaces de tener una amistad "verdadera" (3). La nación mestiza es un medio para conciliar las diferencias. Está representada por una élite blanca o blanqueada que se proclama como la personificación de la voluntad de una nación - como tal, retiene el principio de la autoridad en el hombre blanco sobre los grupos subalternos-.

Sedgwick argumenta que "ha sido aparentemente imposible imaginar una manera de patriarcado que no haya sido homofóbica" (3), sin embargo, no hay evidencia "de que el patriarcado requiera de la homofobia estructuralmente hablando" (4). Ahora bien, el extenso trabajo de Freyre sobre los orígenes del patriarcado brasileño puede no parecer homofóbico, así como puede no parecer racista dado que celebra la flexibilidad sexual y racial de los colonizadores portugueses. Existe en verdad un intento de representar una gradación en el continuum homosocial así como en el racial, que sería muy difícil de imaginar en otras sociedades patriarcales. Freyre, empero, privilegia una forma de hibridación social y cultural que debe siempre sublimarse. Así como los actos homosexuales pueden ser aceptados hasta cierto punto - en la medida en que la homosexualidad sea temporal y sea sublimada a una amistad espiritual-, la negritud o la presencia africana debe también ser un estado transitorio, una fase en la constitución de la subjetividad brasileña y debe ser, entonces, transcendente en nombre del mestizaje cultural o una forma de negritud espiritual, más que genética.

Las estructuras de poder identificadas en las representaciones de raza y sexualidad de Freyre sugieren una interpretación particular de la sociedad brasileña en términos de asimilación y de supresión de la diferencia. De acuerdo con Freyre, la sociedad brasileña se caracteriza por una transición de una historia de esclavitud abortada - una relación que corresponde a un patriarcado y a un 
modelo benevolente de padre-hijo- a un modelo liberal y democrático basado en la igualdad y la fraternidad. El resultado, para Freyre, es una cultura original, facilitada por la élite blanca o mestiza, que media entre la viabilidad de las masas indígenas y africanas, por un lado, y el intelectualismo avanzado de los europeos, por el otro:

Entre estos dos misterios - orden y libertad, de autoridad y de democraciala vida política ha encontrado un equilibrio, una vida que ha transcendido precozmente el régimen del señor y el esclavo. En verdad, el equilibrio continúa entre realidades tradicionales profundas: sádicos y masoquistas, señores y esclavos, doctores e iletrados, individuos cuya cultura es predominantemente europea y otros cuya cultura es principalmente africana o amerindia. Sin ciertas ventajas, concretamente, aquellas que tienen que ver con una dualidad que no es del todo dañina para nuestra cultura en el proceso de desarrollo, esta no es una cultura que se encuentra enriquecida de un lado por la espontaneidad, la frescura de la imaginación y la emoción de los más numerosos y, por otro lado, por el contacto, vía las élites, con la ciencia, la tecnología y el pensamiento avanzado de los europeos. (CGS 52)

Freyre mantiene las antiguas jerarquías a la vez que presenta un modelo que puede verse como democrático; reproduce paradigmas de dominación paternales a la vez que celebra la síntesis que representa la élite fraternal. Su narrativa de democracia racial se construye en la intersección del amor homosocial y fraternal, por un lado, y por el erotismo sadomasoquista y paternalista, por el otro. Por medio de lo que el propio Freyre ha definido como "escritura bisexual" - no ficcional, tampoco científica-, emplea una retórica de la flexibilidad, la tolerancia y la ambigüedad que conduce a la diferencia racial en formas que, en definitiva, legitiman la representación unívoca de una élite que apropia voces heterogéneas antagónicas en la constitución de una subjetividad nacional.

\section{Obras citadas}

Arroyo, Jossianna. "Brazilian Homoerotics: Cultural Subjectivity and

Representation in the Fiction of Gilberto Freyre". Lusosex: Gender and

Sexuality in the Portuguese-Speaking World. Ed. Susan Quinlan and

Fernando Arenas. Minneapolis: U of Minnesota P, 2002. 57-83. Impreso.

Derrida, Jacques. Politiques de l'amitié. París: Galilée, 1994. Impreso.

Fiedler, Leslie. "Come Back to the Raft Ag'in, Huck Honey!". A New

Fiedler Reader. New York: Prometheus Books, 1999-3-12. Impreso.

Freyre, Gilberto. Casa Grande e Senzala (1933). Río de Janeiro: Record, 1995. Impreso. 
Freyre, Gilberto. Dona Sinhá e o Filho Padre. Río de Janeiro:

Editora José Olympio, 1964. Impreso.

Freyre, Gilberto. Manifesto Regionalista. Ed. Fátima

Quintas. Recife: Massangana, 1996. Impreso.

Freyre, Gilberto. O Outro Amor do Dr. Paulo. Río de Janeiro:

Editora José Olympio, 1977. Impreso.

Freyre, Gilberto. Região e Tradição. Río de Janeiro: Record, 1968. Impreso.

Freyre, Gilberto. Tempo Morto e Outros Tempos: Trechos de um

Diário de Adolescência e Primeira Mocidade (1915-1930). Río

de Janeiro: Livraria José Olympo, 1975. Impreso.

Freyre, Gilberto. The Mansions and the Shanties: The Making of Modern

Brazil. Trans. and ed. Harriet de Onis. NY: Knopf, 1968. Impreso.

Kutzinski, Vera M. Sugar's Secrets: Race and the Erotics of Cuban

Nationalism. Charlottesville: UP of Virginia, 1993. Impreso.

Montaigne, Michel de. The Complete Essays of Montaigne. Trad.

Donald M. Frame. Stanford: Stanford UP, 1989. Impreso.

Sedgwick, Eve Kosofsky. Between Men. New York: Columbia UP, 1985. Impreso.

Vianna, Hermano. "Equilíbrio de antagonismos". Folha de São Paulo: Mais! São Paulo, 12 de marzo de 2000. http://www1.folha.uol.com.br/fsp/mais/fs1203200010.htm. Web. 